\title{
GEOCRONOLOGIA DO GABRO DE MATA GRANDE, MUNICÍPIO DE SÃO SEPÉ, ESTADO DO RIO GRANDE DO SUL
}

\author{
ROBERTO SILVA ISSLER*, RENATO ANTONNIO CHDIAY DRESCH** e \\ ARI ROISENBERG***
}

\begin{abstract}
Two K-Ar age determinations has been done in basic rocks of the Mata Grande Area, São Sepé township, State of the Rio Grande do Sul. The basic rocks are gabbros (coronites) and form the central part of a former submarine flow that constitute part of the ophiolitic belt from Cerro da Cria - Mata Grande - Arroio da Cavalhada. These gabbros are old and the results are grouped around $2034 \mathrm{~m} \cdot \mathrm{y}$. Brazil.

This magmatic cycle is an important geotectonic episode of the Precambrian of Southern

INTRODUÇÄO O gabro de Mata Grande ocupa uma área aproximada de $6 \mathrm{~km}^{2}$, com forma ligeiramente alongada, sendo suas dimensões máximas $3,8 \mathrm{~km}$ de comprimento por 2,7 km de largura, tendo a maior dimensão orientada segundo a direção geral NE-SW. Localiza-se na parte leste da quadrícula de Vila Nova, município de São Sepé, Estado do Rio Grande do Sul.

Essas rochas foram estudadas por Issler et al. (1967a) e Issler et al. (1967b).

Com o objetivo de estabelecer a relação de idade dessas rochas com problemas estratigráficos do Pré-Cambriano do Rio Grande do Sul, foram coletadas algumas amostras para datação pelo método potássio-argônio.
\end{abstract}

MÉTODO E PRECISÃo O método potássio-argônio, utilizado no Centro de Pesquisas Geocronológicas de São Paulo, foi descrito por Amaral et al. (1966).

A sua validade e precisão para datação de rochas básicas foram objeto de estudo por inúmeros pesquisadores.

As constantes utilizadas foram as seguintes:

$$
\begin{aligned}
& \lambda K=0,584 \times 10^{-10} \operatorname{anos}^{-1} ; \\
& \lambda \text { tot }=0,530 \times 10^{-9} \operatorname{anos}^{-1} ; \\
& \% \text { atom. } \mathrm{K}^{40} \mathrm{em} K^{\text {tot }}=1,19 \times 10^{-2} .
\end{aligned}
$$

RESULTADOS E CONCLUSÖES As rochas analisadas estão sumariamente descritas no Anexo e sua procedência consta da Fig. 1. Foram coletadas algumas amostras e selecionadas duas, para a datação. A Tab. I resume os resultados obtidos.

Todos os resultados se agrupam em torno de 2034 milhões de anos.

Os resultados obtidos mostram que o ciclo magmático básico do qual o gabro de Mata Grande é parte integra o episódio geotectônico de um vulcanismo básico inicial, cuja idade é, agora, um marco para erigir-se a coluna estratigráfica do Pré-Cambriano do sul do Brasil.

Através de correlação, a idade das rochas básicas de Mata Grande ajustam-se aos dados geocronológicos da área cratônica Uruguai-Argentina, principalmente da costa sul do Uruguai e norte da Argentina, onde idades ao redor de $2000 \mathrm{~m}$.a. foram encontradas pelos métodos Rb-Sr e K-Ar (Hart, 1966).

*Departamento de Geologia do Instituto Central de Geociências da Universidade Federal do Rio Grande do Sul

**Geólogo

***Departamento de Mineralogia e Petrologia do Instituto Central de Geociências da Universidade Federal do Rio Grande do Sul 


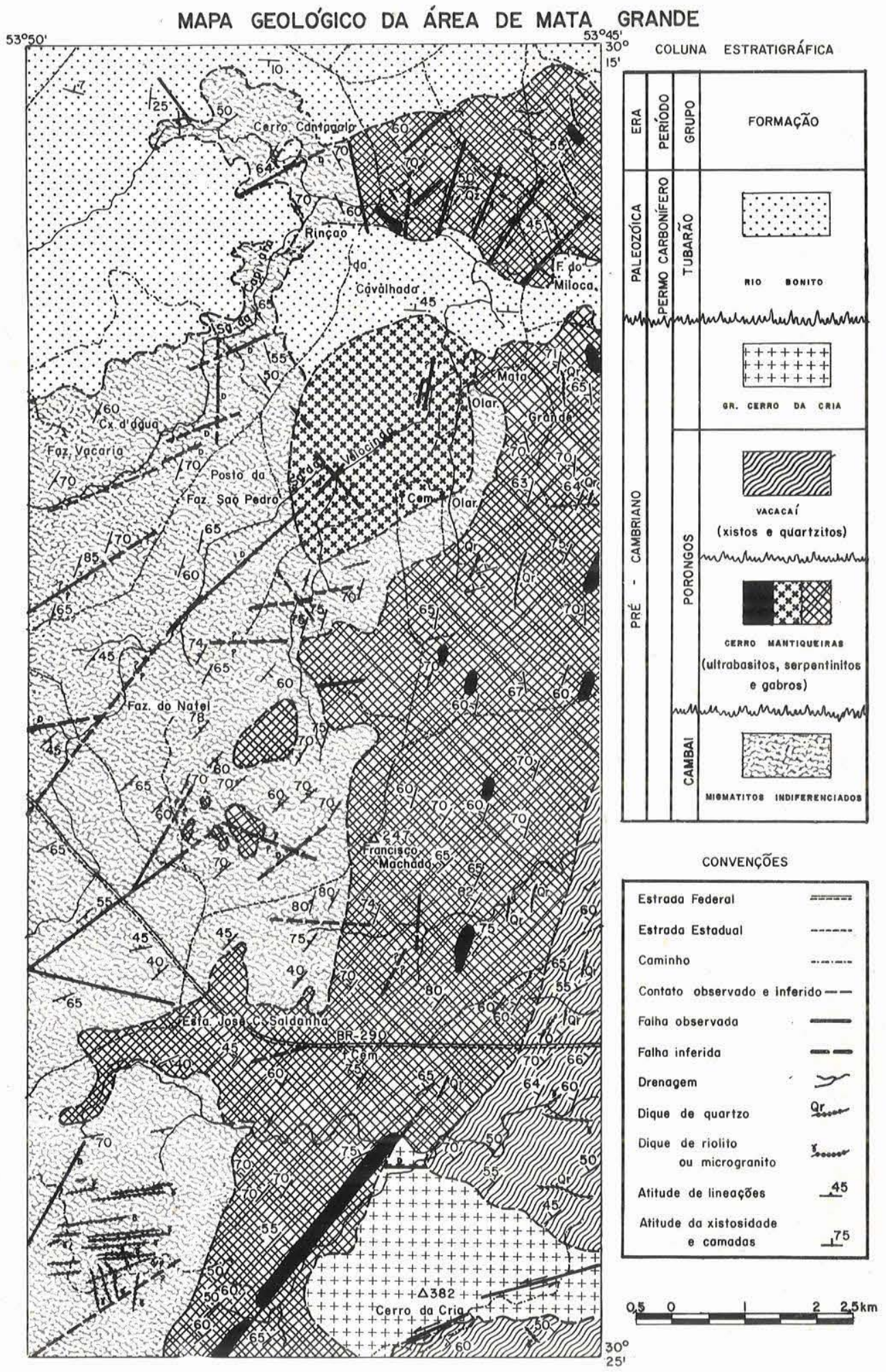

Figura 1 - Mapa geológico da área de Mata Grande 
Deve-se notar que o ciclo orogênico de cerca de 2000 m.a. ocorre além dessas duas áreas cratônicas. Em razão da ampla extensão desse evento, na América do Sul, Hurley et al. (1967) propôs o nome de ciclo orogênico Transamazônico.

Segundo Cordani (1971), as datações obtidas para essa região antiga, denominada Craton do Rio de la Plata, resultaram próximas de 2000 m.a., indicando eventos geológicos relacionados com o ciclo Transamazônico. Os dados disponíveis, até o momento, são ainda insuficientes para as tentativas de interpretação da evolução geológica regional, durante o ciclo em referência, em épocas anteriores.

Geocronologicamente, as rochas básicas de Mata Grande são correlacionáveis com as unidades tectônico-estratigráficas descritas por Ferrando e Fernandez (1971), de idade Limpopo-Kibali, no embasamento da "Cuenca del Rio de la Plata".

As rochas básicas de Mata Grande, na idade, ajustam-se ao evento geológico bem definido do Escudo da Guiana, em torno de 2000 m.a., para o qual foi proposto o nome de episódio Akawaiano, por Snelling e McConnell (1966) em Cordâni atal. (1968).

Os dobramentos "muito antigos" (2000-2 200 m.a.) na América do Sul são os dobramentos Guianiano (Transamazônico, Caribiano), que se manifestam mais energicamente sobre o escudo das Guianas. Os movimentos tardios desses dobramentos foram datados em 1800 m.a., segundo os últimos dados (Bogdanoff, 1969).

Tabela I

\begin{tabular}{lcccccccc}
\hline $\begin{array}{l}\text { N. de } \\
\text { campo }\end{array}$ & Local & Rocha & Material & SPK & $\% \mathrm{~K}$ & $\begin{array}{c}\mathrm{Ar}^{40} \mathrm{rad} \times 10^{-6} \\
\text { cc/g STP }\end{array}$ & $\begin{array}{c}\mathrm{Ar}^{40} \mathrm{~atm}, \\
\%\end{array}$ & Idade \\
\hline \hline RS-4A & $\begin{array}{c}\text { Mata } \\
\text { Grande }\end{array}$ & Gabro & $\begin{array}{c}\text { Plagio- } \\
\text { clásio }\end{array}$ & 2352 & 0,1426 & 23,58 & 9,56 & $2192 \pm 93$ \\
RS-4B & Idem & Idem & $\begin{array}{c}\text { Idem } \\
\text { Idem }\end{array}$ & 2354 & 0,4072 & 52,20 & 9,45 & $1877 \pm 12$ \\
\hline
\end{tabular}

Agradecimentos Agradecemos ao Instituto de Geociências da Universidade de São Paulo, pelo estágio, que possibilitou os dados do presente trabalho; também ao Dr. Umberto G. Cordani, ao físico Koji Kawashita e aos técnicos Cláudio dos Santos, Maria Elisa Lucena e José Roberto Medeiros, todos do Centro de Pesquisas Geocronológicas, pelo auxílio nas análises de potássio e argônio. Ao Dr. Paulo Miranda de Figueiredo Filho, pelo empenho demonstrado na solução de problemas estratigráficos do Pré-Cambriano do Rio Grande do Sul, e por conseguir oportunidade de estágio que originou este e outros dados geocronológicos.

\section{BIBLIOGRAFIA}

AMARAL, G., CORDANI, U. G., KAWASHITA, K. e REYNOLDS, J. H. - 1965 - Potassium-argon dates of basaltic rocks from Southern Brazil. Geoch. Cosm. Acta, 30, 154-180

BOGDANOFF, A. A. - 1969 - Époques tectoniques: à propos de la subdivision en periodes de l'histoire tectonique de la croûte terrestre. Bull. Soc. Géol. Fr., XI(5): 717-728

GORDANI, U. G., MELGHER, G. C. e ALMEIDA, F. F. M. de - 1968 - Outline of the Precambrian geochronology of South America. Canadian Jour. of Earth Sc., 5: 629-632

CORDANI, U. G. - 1971 - Síntese da Geocronologia Pré-Cambriana da Região Costeira Atlântica Meridional da América do Sul. XXV Congresso Brasileiro de Geologia. Soc. Bras. de Geologia. Bol. Especial n. ${ }^{\circ}$ 1, pp. 179-180

FERRANDO, L. A. e FERNANDEZ, A. N. - 1971 - Esquema Tectônico Cronoestratigráfico Del Predevoniano En Uruguay. Univ. de la República. Fac. de Agronomia, pp. 1-18

HART, S. R. - 1966 - Radiometric ages in Uruguay and Argentina and their implications concerning continental drift (Abstr.). Geol. Soc. Am., Program, 1966. Annual Meeting, San Francisco, California, p. 86

HURLEY, P. M., ALMEIDA, F. F. M. de, MELCHER, G. G., CORDANI, U. G., RAND, J. R., 
KAWASHITA, K., VANDOROS, P., PINSON, W. H. Jr, e FAIRBAIRN, H. W. - 1967 Test of continental drift by comparison of radiometric ages. Science, 157 (3 788): 495-500 ISSLER, R. S., BURGER Jr. C. e ROISENBERG, A. - 1967 - Coronito da Área de Mata Grande, Município de São Sepé, Estado do Rio Grande do Sul (resumo). XXI Congresso Brasileiro de Geologia. Bol. Paranaense de Geociências, n. ${ }^{\circ}$ 26, pp. 37-38

ISSLER, R. S., BURGER Jr., C. e ROISENBERG, A. - 1967 - Coronito da Área de Mata Grande, Município de São Sepé, Estado do Rio Grande do Sul, Soc. Bras. Geologia, Anais do XXI Congresso Brasileiro de Geologia, pp. 182-197

Rocha com coloração cinza-médio-escuro (N4 - Rock-Color Chart, GSA, 1970) estruturalmente maciça, apresentando, entretanto, abundantes microfraturamentos radiais centrados em olivina serpentinizada. Textura granular média, com granulometria de 2,0 a 3,0 mm e arranjo subofitico de plagioclásio e piroxênio. Os máficos mostram extraordinário desenvolvimento de textura quelifítica com núcleos de olivina.

O plagioclásio é subédrico, incolor e límpido, fracamente sericitizado ao longo dos microfraturamentos, com composição média $A b_{42}$, birrefringência $=0,008$ e $2 V(+)=75^{\circ}-80^{\circ}$.

A olivina é anédrica, incolor, intensamente recortada por veios de serpentina, com magnetita, birrefringência $=0,033-0,034,2 \mathrm{~V}(-)=80^{\circ}-85^{\circ}$, correspondendo a $\mathrm{Fo}_{65-75}$. Geralmente apresenta-se aureolada por franjas completas ou incompletas de piroxênio e mais externa a hornblenda.

O piroxênio dominante é clinopiroxênio augítico verde-pálido, intersticial a trama de plagio-

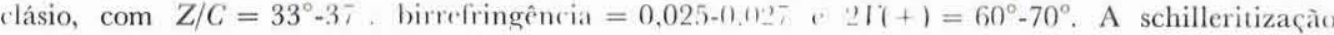
epitáxica é comum e a uralitização fraca.

O ortopiroxênio é bronzita com 15 a $20 \%$ de $\mathrm{FeSiO}_{3}$, forma intersticial, coloração rosa-amarronzada a verde-clara, birrefringência $=0,010-0,012,2 V(+)=75^{\circ}-85^{\circ}$. A schilleritização é constante e a uralitização fraca.

A hornblenda forma auréolas em torno da olivina ou do piroxênio com coloração marrom dominante, menos comumente, verde-pálida, pleocroísmo moderado. birrefringência $=0,018-0,020$, $21^{\circ}=-70^{\circ}$ a $-80^{\circ} \times Z / C=23-25$

A biotita é desprezivel, marrom-avermelhada, inclusa em málicos, com birrefringência $=$ $=0,035-0,036$.

A serpentina é de crisotilo e antigorita, com coloração verde-média, sem pleocroísmo, com birrefringência $=0,009-0,010$ e $2 V(-)=50^{\circ}-55^{\circ}$ para antigorita.

A clorita é penina, verde-pálida, pouco pleocróica, associada a serpentina, com birrefringência $=0,003-0,005, U(-), X A A=0^{\circ}$.

$\mathrm{O}$ talco é incolor, constituindo lamelas em mistura com o agregado de serpentina, clorita e magnetita, originando-se de olivina, mostrando birrefringência $=0,040$ e $2 \mathrm{~V}$ não-mensurável.

Os minerais opacos são dominantemente magnetita secundária associada, como pontuações anédricas, com os produtos de alteração dos máficos.

Análise modal

\begin{tabular}{lcc}
\multicolumn{1}{c}{ Amostra } & $R S-4-A$ & $R S-4-B$ \\
\hline Plagioclásio & $71,6 \%$ & $61,3 \%$ \\
Clinopiroxênio & $5,1 \%$ & $2,8 \%$ \\
Ortopiroxênio & $2,4 \%$ & $1,7 \%$ \\
Hornblenda & $2,6 \%$ & $1,4 \%$ \\
Olivina & $14,6 \%$ & $20,1 \%$ \\
Serpentina & $1,9 \%$ & $7,3 \%$ \\
Clorita & $0,8 \%$ & $2,8 \%$ \\
Minerais Opacos & $1,0 \%$ & $2,6 \%$ \\
Biotita e talco & Despreziveis & Despreziveis \\
\hline Total & $100,0 \%$ & $100,0 \%$
\end{tabular}

Diagnóstico: olivina gabro quelifítico. 